\title{
Ciclo de charlas de ultrasonido, una experiencia "online" del pandémico año 2020
}

\author{
María Francisca Norambuena $P^{1}$, Rolando Cocio $A^{2 *}$, Juan Casas M. ${ }^{3}$
}

1. Médico Radiólogo. Clínica Alemana de Santiago. Hospital San Juan de Dios. Santiago, Chile.

2. Médico Radiólogo. Profesor asistente adjunto Universidad del Desarrollo. Clínica Alemana de Santiago. Hospital San Juan de Dios. Santiago, Chile.

3. Médico Radiólogo. Clínica Alemana de Santiago. Hospital Clínico Universidad de Chile. Santiago, Chile.

"Es martes y ya estamos listos para iniciar una nueva jornada de ultrasonido". Así comenzaba el evento, todos los martes desde las 20:00 horas, entre agosto y diciembre del año 2020. En la hora previa a la jornada, se probaban cámaras, sonido y se ensayaban los últimos detalles para una presentación sin incidentes. $Y$ no existieron inconvenientes que nublaran la reunión. Con gran audiencia que esperaba con ansias el horario, en algunas ocasiones con más de 480 espectadores, se efectuaron las transmisiones para presenciar los más interesantes temas de ecografía.

Fue una tarea desafiante desde su concepción, elaborada en conjunto con el capítulo de ultrasonido y con mucho entusiasmo, en la que se logró reunir a representantes de 12 universidades a lo largo de todo Chile, con más de 30 docentes, y espectadores de varios países de Hispanoamérica, entre ellos, los pertenecientes a sociedades en convenio de Argentina, Perú, Ecuador, México y Uruguay.

La pandemia del coronavirus exigía adaptarse a los cambios y el capítulo de ultrasonido estuvo a la altura. Migramos de reuniones presenciales a Seminarios Web, a través de una plataforma virtual que entregó acceso a socios que antiguamente tenían dificultades de acceso y se logró transformar la amenaza en oportunidad, configurando esta modalidad de difusión de conocimientos, como una fortaleza de los nuevos tiempos.

Con dos charlas de veinte minutos por sesión y 10 minutos para la interacción con el auditorio virtual y preguntas, se llevaron a cabo las 16 charlas. Los temas tratados fueron diversos, enfocados en los tópicos ultrasonográficos de mayor interés y dirigidos al aprendizaje de los residentes de radiología y de los radiólogos generales. Charlas como urgencias abdominales, pediátricas y musculoesqueléticas, nuevos avances en ecografía como la elastografía hepática y la estandarización de estudios prequirúrgicos vasculares o de neoplasia tiroidea, entre otros, orientaron a los asistentes.

Durante las sesiones, el canal de comunicación entre los anfitriones, expositores y auditorio fue fluido. A través de las encuestas a la audiencia con los "takehome points" de las sesiones y las preguntas del chat, se logró satisfacer las principales interrogantes de los radiólogos asistentes, contestadas en la sesión en vivo, o bien de forma diferida, cuando el tiempo apremiaba.

Fueron charlas de excelencia, con información concisa y precisa para la práctica radiológica diaria.

La experiencia de organización fue desafiante. Siempre existía la posibilidad de que algo fallara, el internet, los expositores o los asistentes, pero con dedicación y esfuerzo se pueden hacer eventos de alta calidad. No se dejó nada al azar, cada lunes previo a las charlas se realizaba una reunión de pauta, resolviendo dudas, acercando la plataforma a los expositores y empapando del proyecto a los participantes. Y así, martes a martes, aparecían nuevas caras y otras no tanto, pero con todas las ganas de acercar el núcleo del conocimiento a los lugares más recónditos de nuestro país y de nuestro continente.

Quizás lo más apasionante del proyecto es lograr llevar a cabo un trabajo de alto estándar con tantos exponentes nacionales, todos enfocados en un único objetivo, estandarizar nuestros conocimientos en el arte del diagnóstico ecográfico.

Agradecemos a la Sociedad Chilena de Radio- 
logía por todo el apoyo brindado, y especialmente a todos los docentes que participaron, haciendo de ésta una instancia de aprendizaje provechosa y de encuentro en medio de la pandemia. $Y$ a todos nuestros asistentes, gracias por su presencia y cordiales comentarios al finalizar cada sesión.

Norambuena M. Ciclo de Charlas de Ultrasonido, una experiencia "online" del pandémico año 2020. Rev Chil Radiol 2021; 27(2): 56-57.

${ }^{\star}$ Correspondencia: Rolando Cocio / rcocio@alemana.cl 